\title{
Análise das propriedades superficiais do aço inoxidável ABNT 304 modificado por implantação iônica por imersão em plasma de nitrogênio em alta temperatura
}

\author{
Surface properties analysis of stainless steel AISI 304 modified by nitrogen high temperature \\ plasma immersion ion implantation
}

\author{
Samantha F. M. Mariano ${ }^{1}$, Alberto L. Santos², Mario Uedaํ, Rogério M. Oliveira ${ }^{1}$
}

\begin{abstract}
Resumo
Amostras da liga de aço inoxidável ABNT 304 foram tratadas por implantação iônica por imersão em plasma (3IP) de nitrogênio em duas condições de temperatura: $480^{\circ} \mathrm{C}$ e $650^{\circ} \mathrm{C}$. As superfícies modificadas foram analisadas por Difratometria de Raios X (DRX), Microscopia Eletrônica de Varredura (MEV) e Microscopia de Força Atômica (MFA). A dureza, o comportamento tribológico e de corrosão foram avaliados através de ensaios de microdureza Vickers, ensaio pino sobre disco e de polarização potenciodinâmica, respectivamente. Apesar de ter sido observada a precipitação de cromo em contornos de grãos do aço, o que evidentemente reduziu sua resistência à corrosão, foram identificados picos intensos de austenita expandida nas amostras tratadas a $650^{\circ} \mathrm{C}$, as quais apresentaram valores de dureza mais elevados e boa resistência ao desgaste quando comparadas às amostras tratadas a $480^{\circ} \mathrm{C}$.
\end{abstract}

Palavras-chave: Implantação iônica por imersão em plasma; Aço inoxidável; Austenita expandida.

\begin{abstract}
Samples of AISI 304 stainless steel alloy were treated via nitrogen high temperature plasma immersion ion implantation (PIII) in two different experimental conditions: at $480^{\circ} \mathrm{C}$ and $650^{\circ} \mathrm{C}$. The modified surfaces properties were analyzed by X-ray Diffraction (XRD), Scanning Electron Microscopy (SEM) and Atomic Force Microscopy (AFM). Hardness, tribological and corrosion behaviors were evaluated by means of microhardness Vickers and pin-on-disk tests, and potentiondynamic polarization, respectively. Regardless of chromium precipitation into grain boundaries reducing the corrosion resistance of the stainless steel, high $\gamma N$ intense peaks were observed in the samples treated at $650^{\circ} \mathrm{C}$, which exhibited hardness values and wear resistance greater than those modified at $480^{\circ} \mathrm{C}$.
\end{abstract}

Keywords: Plasma immersion ion implantation; Stainless steel; Expanded austenite.

${ }^{1}$ Instituto Nacional de Pesquisas Espaciais (INPE) - São José dos Campos/SP - Brasil.

${ }^{2}$ Universidade Estadual Paulista Júlio de Mesquita Filho (UNESP) - Guaratinguetá, SP - Brasil.

Autor correspondente: Samantha Mariano - samantha.magalhaes@plasma.inpe.br 


\section{Introdução}

As ligas de aço inoxidável austenítico possuem propriedades bastante apropriadas para aplicações em indústrias, como a sua excelente resistência à corrosão, que é atribuída naturalmente ao fenômeno da passivação. Porém, para aplicações tribológicas, suas propriedades não despertam grande interesse. Sua microestrutura, que é determinada pelo teor dos elementos ligantes, pode conferir ao metal distintas propriedades de resistência mecânica e à corrosão.

Nesse sentido, com o objetivo de reforçar seu desempenho tribológico, vários trabalhos na literatura vêm recomendando tratamentos da superfície baseados, principalmente, na implantação iônica por imersão em plasma $^{(1-5)} \mathrm{e}$ na nitretação ${ }^{(5-8)}$, formando camadas endurecidas ricas em austenita expandida $\left(\gamma_{N}\right)$. A fase $\gamma_{N}$ é conhecida por melhorar as propriedades superficiais do aço e, desta maneira, estender sua aplicação para situações onde o uso de superfícies mais resistentes ao desgaste é imprescindível ${ }^{(9)}$.

Em contrapartida, a temperatura é um fator limitante em tais tratamentos, pois ao mesmo tempo em que exerce forte influência na taxa de difusão, não se deve exceder a faixa de precipitação do cromo $\left(\sim 550^{\circ} \mathrm{C}\right)$, a fim de que a condição de passividade no aço seja mantida.

Na presença de oxigênio, forma-se naturalmente uma fina camada passiva na superfície do aço inoxidável, constituída por óxidos de cromo $\left(\mathrm{Cr}_{2} \mathrm{O}_{3}\right)$, a qual atua como uma barreira entre a liga e o meio, conferindo-lhe proteção contra a corrosão. Como consequência da precipitação de fases ricas em cromo em temperaturas muito altas, ocorre o empobrecimento de $\mathrm{Cr}$ nas regiões da matriz vizinhas ao precipitado. A passivação nestas regiões é, portanto, prejudicada já que grande parte de $\mathrm{Cr}$ da matriz passa a formar novas fases, reduzindo a formação natural de $\mathrm{Cr}_{2} \mathrm{O}_{3}$, ou seja, diminuindo o caráter de proteção do metal quando exposto no ambiente. Com isso, a diferença de potencial entre a fase precipitada e sua região adjacente eleva as taxas de corrosão ${ }^{(10)}$.

Neste trabalho, são apresentados os resultados obtidos usando-se um sistema 3IP de alta temperatura como proposto por Oliveira et al ${ }^{(11)}$, em que o tratamento afeta a microestrutura do aço inoxidável 304 bem como sua dureza, e desempenhos corrosivo e tribológico, além de ser destacada a viabilidade desta técnica, quando é empregada em temperaturas ainda mais elevadas e destinada à aplicações nas quais a proteção contra ambientes corrosivos não é um requisito primordial.

\section{Materiais e Métodos}

Na Fig. 1 está representado o arranjo experimental do sistema 3IP de alta temperatura utilizado neste trabalho. Mais informações e detalhes sobre este sistema podem ser encontrados em outro trabalho ${ }^{(11)}$.

O sistema consiste, basicamente, de: uma câmara de aço inoxidável com entrada para injeção do gás de trabalho; o sistema de vácuo composto por uma bomba mecânica e uma bomba difusora; um porta-amostras, que é polarizado negativamente e atua como ânodo da descarga; além de uma fita de tântalo que faz o papel do catodo. Neste sistema, o substrato é bombardeado com os elétrons que são liberados pelo catodo através de emissão termiônica, sendo assim aquecidos. Além disso, o catodo favorece a ruptura da descarga devido ao rápido aumento do grau de ionização do gás. É válido destacar que grande parte do ciclo de trabalho, cerca de $98 \%$, é aproveitado para aquecer o substrato, enquanto que no restante ocorre de fato a implantação ${ }^{(11)}$.

Em cada tratamento foram usadas cinco amostras polidas de aço inoxidável ABNT 304 (15 mm de diâmetro e 2-3 mm de espessura) que, após serem limpas em banho ultrassônico, foram fixadas no porta-amostras. Inicialmente, as amostras foram bombardeadas com plasma de argônio com o objetivo de remover óxidos e impurezas presentes na superfície e facilitar a implantação dos íons de nitrogênio, na etapa subsequente. A seguir, as amostras foram implantadas com nitrogênio conforme a temperatura usada em cada tratamento, como apresentado na Tabela 1.

A pressão de trabalho foi mantida a $0.6 \mathrm{~Pa}$ em ambos os experimentos. $\mathrm{O}$ controle da temperatura dos substratos foi feito por meio da variação do potencial aplicado ao

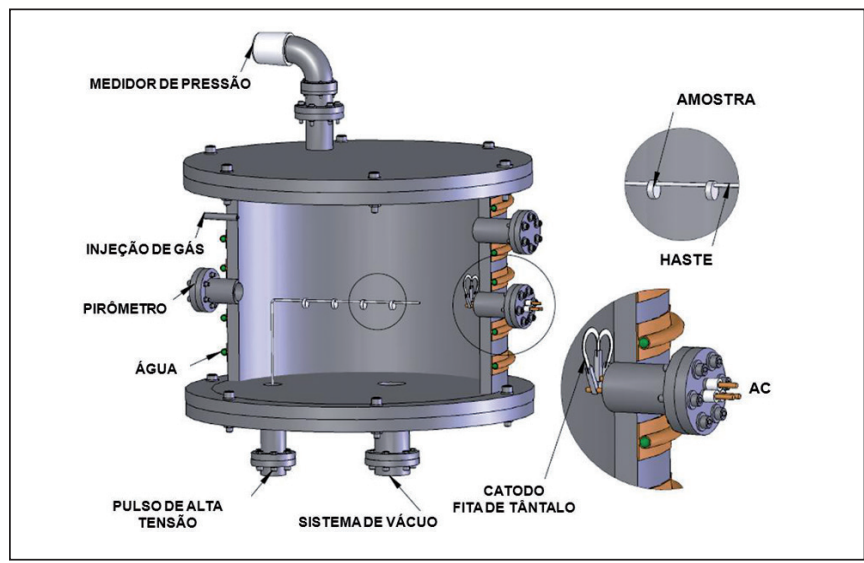

Figura 1. Esquema do sistema 3IP em alta temperatura. 
Tabela 1. Condições experimentais.

\begin{tabular}{|c|c|c|c|c|c|}
\hline Tratamento & $\begin{array}{c}\text { Temp. } \\
\left({ }^{\circ} \mathbf{C}\right)\end{array}$ & $\begin{array}{c}\text { Tensão } \\
(\mathbf{k V})\end{array}$ & $\begin{array}{c}\text { Largura } \\
\text { de pulso } \\
(\boldsymbol{\mu s})\end{array}$ & $\begin{array}{c}\text { Freq. } \\
(\mathbf{H z})\end{array}$ & $\begin{array}{c}\text { Tempo } \\
(\mathbf{m i n})\end{array}$ \\
\hline $1^{\circ}$ & 480 & 5 & 40 & 400 & 60 \\
\hline $2^{\circ}$ & 650 & 5 & 40 & 400 & 60 \\
\hline
\end{tabular}

catodo, sendo esta monitorada com um pirômetro ótico da Mikron (modelo M90-Q).

As superfícies modificadas foram analisadas por Microscopia Eletrônica de Varredura (MEV) com o equipamento JEOL modelo JSM-S310, no modo elétrons-secundários, para observar mudanças na microestrutura. As novas fases formadas foram identificadas por um Difratômetro de Raios X (Cuk $\alpha$ ) da marca PANALYTICAL e modelo $\mathrm{X}^{\prime}$ pert Powder, no modo Bragg Brentano. Os espectros foram obtidos com $2 \theta$ variando entre $30^{\circ}$ e $100^{\circ}$, tempo de integração de 10 segundos e $0,02^{\circ}$ de passo.

Para estimar o perfil de dureza das superfícies, os ensaios de microdureza Vickers foram realizados com um equipamento da Future-Tech, variando-se a carga aplicada de 25 gf a 500 gf. O comportamento tribológico das superfícies foi estudado através de ensaio pino-sobre-disco, utilizando-se esfera de alumina com $3 \mathrm{~mm}$ de diâmetro, velocidade linear de $5 \mathrm{~cm} / \mathrm{s}$ e carga de $1 \mathrm{~N}$. As trilhas de desgaste foram medidas com um perfilômetro da Tencor modelo Alpha Step 500. Quanto a resistência à corrosão, esta foi avaliada por meio de ensaio de polarização potenciodinâmica com o potenciostato Autolab. Foi utilizado um eletrodo de referência de prata/cloreto de prata $(\mathrm{Ag} / \mathrm{AgCl})$ e um contra eletrodo de platina imersos em solução salina $(3,5 \% \mathrm{NaCl})$ a temperatura ambiente e sem agitação. A velocidade de varredura foi de $0,33 \mathrm{mV} / \mathrm{s}$ e a faixa de potencial de $-100 \mathrm{mV}$ até $500 \mathrm{mV}$.

\section{Resultados e Discussão}

Difratometria de Raios X

Após serem implantadas com nitrogênio, todas as superfícies foram analisadas por DRX. Em todas as amostras foi observada uma tendência à formação das novas fases, o que pode ser verificado com o difratograma representativo de cada experimento, como é mostrado na Fig. 2.

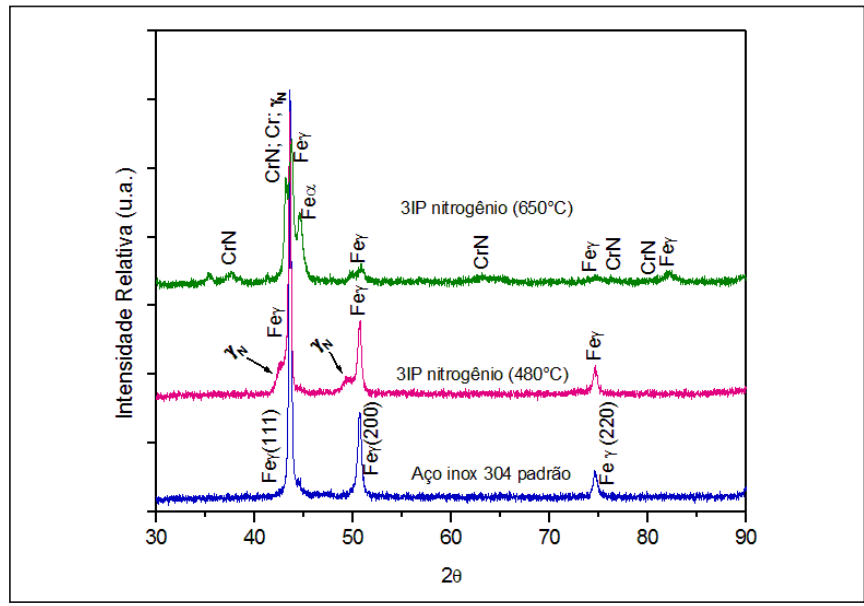

Figura 2. Difratograma do aço inoxidável 304 após tratamento por 3IP.

$\mathrm{Na}$ amostra sem tratamento, os picos são característicos do ferro austenítico (Fe $\gamma)$. O primeiro pico que apa-

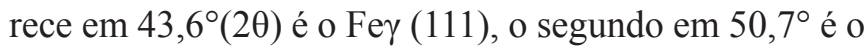
Fe $\gamma(200)$ e o terceiro pico em aproximadamente $74,6^{\circ}$ é o Fey (220). Os picos de Cr puro por serem muito próximos dos picos do Fe $\gamma$ não foram identificados no difratograma da amostra padrão.

As amostras tratadas em baixa temperatura $\left(480^{\circ} \mathrm{C}\right)$ apresentaram picos da matriz bem parecidos com os da amostra sem tratamento, indicando que não houve deslocamento dos picos. Neste espectro, são observados também picos de $\gamma_{N}$ a $42,7^{\circ}$ e $49,4^{\circ}$, adjacentes aos picos de Fe $\gamma$. Destaca-se ainda que os picos da austenita expandida são mais largos e estão posicionados em ângulos meno-

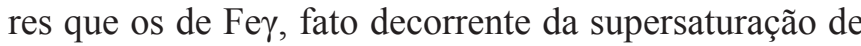
nitrogênio na liga e, consequentemente, da tensão causada pelos íons de nitrogênio, sugerindo uma distorção na rede cristalina cúbica de face centrada (CFC) do aço como apresentado por outros autores ${ }^{(3,4,7)}$.

No espectro do segundo tratamento $\left(650^{\circ} \mathrm{C}\right)$, é possível se observar claramente picos de nitreto de cromo $(\mathrm{CrN})$ e cromo puro juntamente com a austenita expandida.

As linhas de difração de $\mathrm{CrN}, \mathrm{Cr}$ puro e $\gamma_{\mathrm{N}}$ coincidem no espectro por isso foram identificadas a aproximadamente $2 \theta=43,2^{\circ}$. Além disso, os difratogramas revelam que os picos de austenita expandida $\left(\gamma_{\mathrm{N}}\right)$ são mais intensos nas ligas tratadas por 3IP a $650^{\circ} \mathrm{C}$, enquanto que as linhas de difração do $\mathrm{Cr}$ e CrN são menos intensas que os picos de $\gamma_{\mathrm{N}}$ neste mesmo espectro. Uma intensidade maior de picos de austenita expandida na amostra tratada a $650^{\circ} \mathrm{C}$ indica uma difusão acentuada de nitrogênio, o que, acompanhada da presença de fases de nitretos de cromo, implicou no considerável endurecimento destas amostras como será apresentado no tópico a seguir. 
Morfologia, microestrutura e dureza

Após o $2^{\circ}$ tratamento 3IP, todas as amostras apresentaram coloração alaranjada, com algumas regiões mais escuras. A principal informação extraída das micrografias é o aumento evidente da rugosidade (Fig. 3).

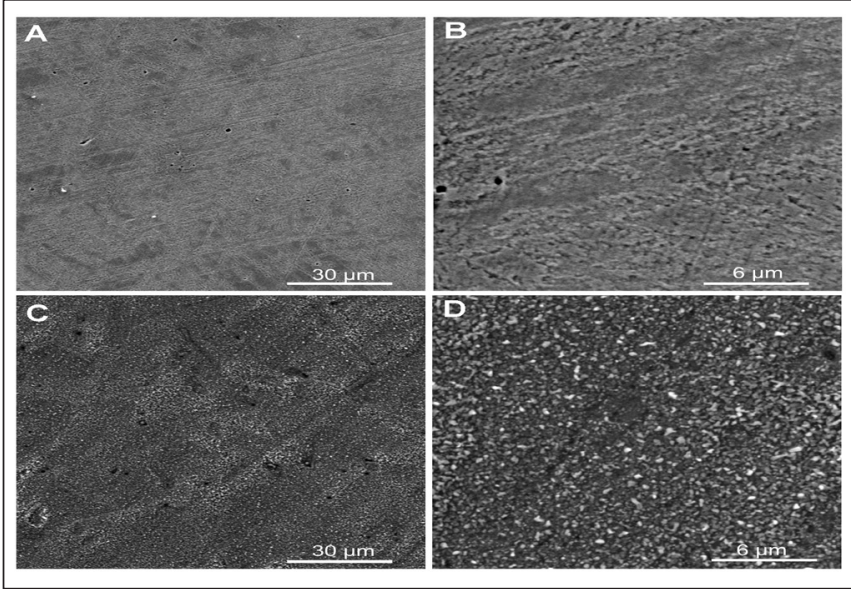

Figura 3. Imagens obtidas por MEV a) Amostra tratada a $480^{\circ} \mathrm{C}$ aumento de $\left.1000 \mathrm{X}, \mathrm{b}\right)$ aumento de $5000 \mathrm{X}$,

c) Amostra tratada a $650^{\circ} \mathrm{C}$ aumento de $1000 \mathrm{X}$ e d) aumento de $5000 \mathrm{X}$.

Como é possível observar nas micrografias apresentadas na Fig. 4, após o tratamento a $650^{\circ} \mathrm{C}$, os contornos de grão da liga ficaram bem evidentes e destacados em tonalidades mais escuras que o interior do grão, indicando a migração de cromo para estas regiões. Esta microestrutura de defeitos contribui para a difusão do nitrogênio, e para a migração dos átomos de $\mathrm{Cr}$ durante o tratamento. A presença de nitretos de cromo e de cromo puro indicada na micrografia é confirmada pelos resultados de DRX. Será interessante realizar um estudo mais detalhado sobre a espessura da camada modificada e seus efeitos no endurecimento do material a partir de análises por AES (Auger Electron Spectroscopy).
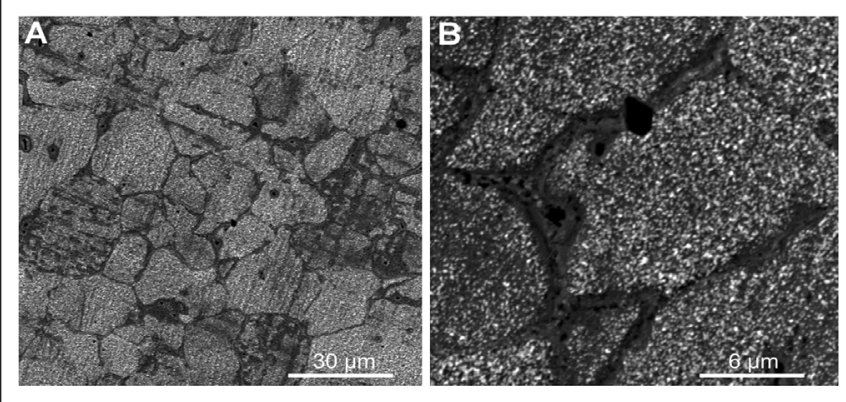

Figura 4. Aço inox 304 tratado a $650^{\circ} \mathrm{C}$ a) $1000 \mathrm{X}$, b) $5000 \mathrm{X}$.
Na Fig. 5, a seguir, é apresentada a imagem obtida por AFM da superfície de uma amostra após o tratamento realizado a $650^{\circ} \mathrm{C}$. A imagem revela os efeitos da implantação de nitrogênio na superfície do aço, caracterizando uma topografia bastante irregular. Nesta região a rugosidade média foi de $38,1 \mathrm{~nm}$.

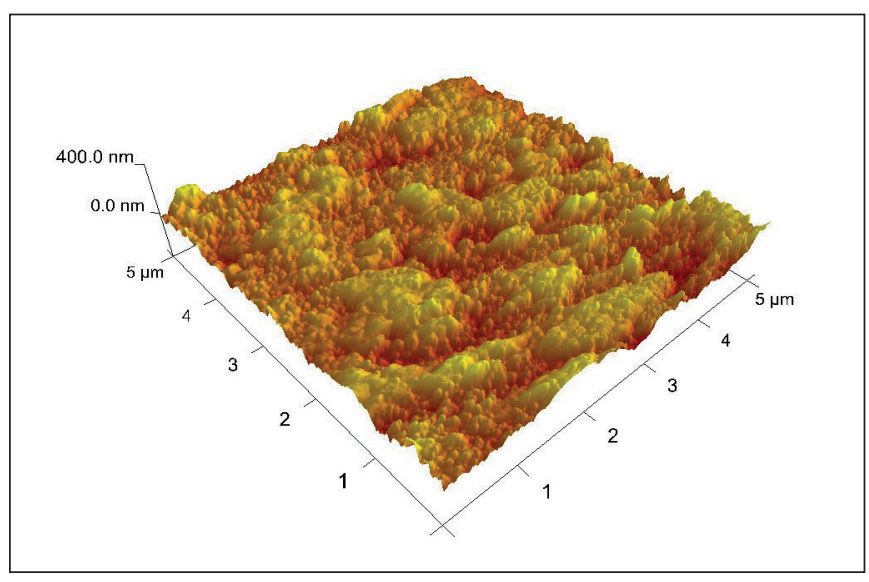

Figura 5. Topografia do aço inox 304 após $3 \mathrm{IP}$ a $650^{\circ} \mathrm{C}$ obtida por AFM.

Ensaios de nanoindentação foram realizados em algumas amostras do segundo tratamento $\left(650^{\circ} \mathrm{C}\right)$, no entanto a alta rugosidade apresentada não estava adequada ao tipo de ensaio e, por isso, influenciaram os valores obtidos de dureza. Portanto, foram utilizados os resultados obtidos por microdureza Vickers, como é mostrado na Fig. 6.

Como já discutido anteriormente, o tratamento 3IP realizado em alta temperatura $\left(650^{\circ} \mathrm{C}\right)$ conduziu à formação de fases de nitreto de cromo e austenita expandida na matriz do aço, resultando em um aumento de $98 \%$ no valor de dureza da liga comparada à liga sem tratamento,de acordo com os resultados da Fig. 6 .

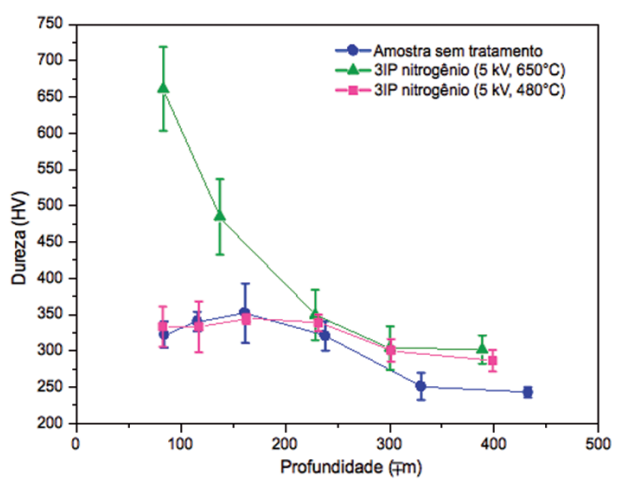

Figura 6. Perfil de microdureza das amostras tratadas por 3IP. 
Atrito e desgaste

Os resultados dos ensaios de tribologia são mostrados na Fig. 7. Para cada condição, a taxa de desgaste foi calculada de acordo com a norma ASTM G-99(12).

Houve redução do coeficiente de fricção médio (cfm) que variou de 0,73 (padrão) para 0,25 , referente às amostras implantadas a $650{ }^{\circ} \mathrm{C}$, enquanto o desgaste foi reduzido em $84 \%$. Por outro lado, as superfícies modificadas a $480{ }^{\circ} \mathrm{C}$ apresentaram perfis de cfm próximo ao do padrão e uma redução de apenas $8 \%$ na taxa de desgaste. Na Tabela 2 constam os valores de taxa de desgaste calculados para cada amostra.

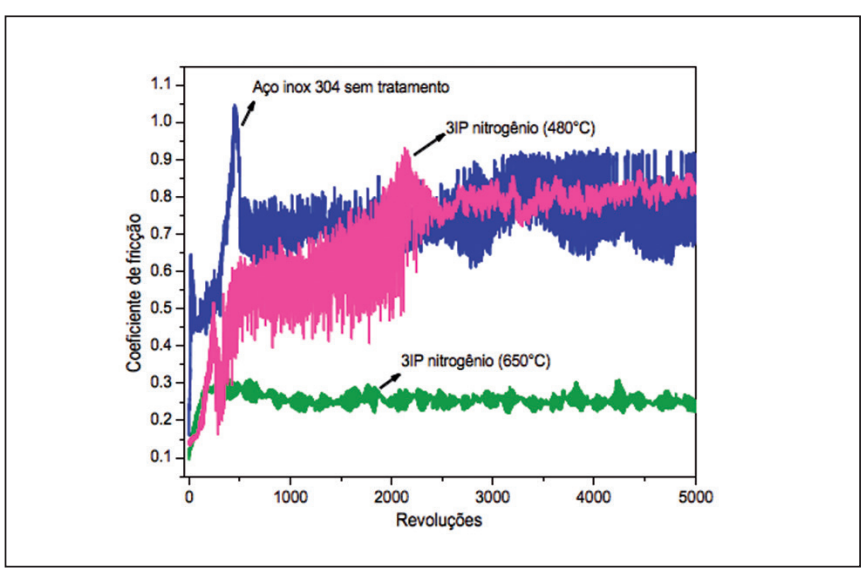

Figura 7. Curvas de atrito obtidas após ensaio de pino-sobre-disco..

Tabela 2. Taxa de desgaste.

\begin{tabular}{|c|c|c|c|c|}
\hline Tratamento & $\begin{array}{c}\text { Carga } \\
(\mathbf{N})\end{array}$ & Revoluções & $\begin{array}{c}\text { Largura } \\
\text { da trilha } \\
(\boldsymbol{\mu m})\end{array}$ & $\begin{array}{c}\text { Taxa de } \\
\text { desgaste } \\
\left(\mathbf{m m}^{3} / \mathbf{N} . \mathbf{m}\right)\end{array}$ \\
\hline padrão & 1,0 & 5000 & $157 \pm 22$ & $4,3 \times 10^{-5}$ \\
\hline $480{ }^{\circ} \mathrm{C}$ & 1,0 & 5000 & $153 \pm 9$ & $4,0 \times 10^{-5}$ \\
\hline $650{ }^{\circ} \mathrm{C}$ & 1,0 & 5000 & $88 \pm 13$ & $6,7 \times 10^{-6}$ \\
\hline
\end{tabular}

\section{Corrosão}

A formação de novas fases ricas em cromo durante o tratamento a $650^{\circ} \mathrm{C}$, como visto pela análise de DRX e nas imagens obtidas por MEV, prejudicaram a resistência à corrosão do material, resultando em uma redução do potencial corrosivo. Já com tratamento em temperatura mais baixa a $480^{\circ} \mathrm{C}$ foi possível manter o perfil de resistência à corrosão do material, sem prejudicar esta propriedade. As curvas de polarização são apresentadas na Fig. 8 .

Foram observados potenciais de corrosão menos nobres nas amostras tratadas a $650^{\circ} \mathrm{C}(-386 \mathrm{mV})$ do que para a amostra padrão $(-290 \mathrm{mV})$, o que significa que o segundo experimento tornou o aço mais suscetível à corrosão. A princípio, as imagens obtidas por MEV indicam para este caso a ocorrência de corrosão intergranular, ou seja, o material é corroído preferencialmente ao longo dos contornos de grão devido à diferença de potencial entre esta região e a matriz da liga.

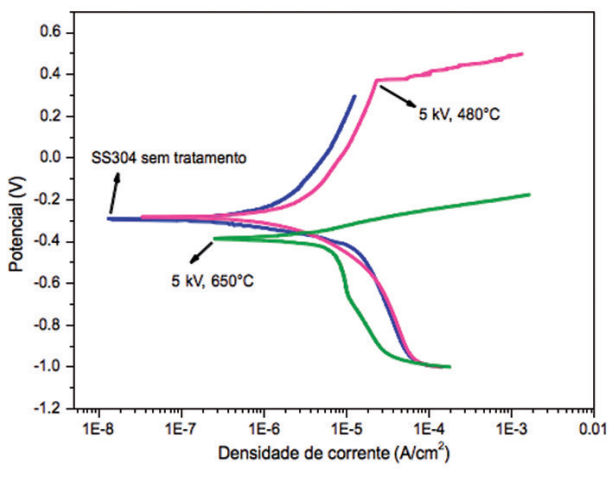

Figura 8. Curvas de polarização potenciodinâmica do aço inox 304 após 3IP de nitrogênio.

\section{Conclusões}

Em todas as técnicas empregadas neste trabalho para caracterizar as superfícies, foi possível observar propriedades muito semelhantes entre as amostras modificadas a $480^{\circ} \mathrm{C}$ e a liga não tratada. Nesta faixa de temperatura, a dose de íons implantados pode ter sido insuficiente para promover a redução da fricção na superfície e também para formar as fases que contribuem para o endurecimento do material, haja vista que houve uma redução pouco significativa da taxa de desgaste (apenas $8 \%$ ). $O$ tratamento não prejudicou a propriedade de proteção contra à corrosão do material, como esperado devido à não formação de $\mathrm{CrN}$ e de precipitados de Cr conforme foi mostrado com os resultados de difratometria.

Para obter superfícies com melhor desempenho nesta temperatura de operação, seria interessante usar tratamentos mais longos e/ou aplicar pulsos com tensões mais altas (da ordem de $10 \mathrm{kV}$ ) a fim de tornar os íons mais energéticos e favorecer a difusão do nitrogênio durante o 3IP. 
Já o processo 3IP em alta temperatura destacou-se por resultar em boas melhoras nas propriedades tribológicas do material o que está relacionado ao aumento da difusividade do nitrogênio no substrato. $\mathrm{A} 650^{\circ} \mathrm{C}$ foi possível reduzir o coeficiente de atrito, melhorar a resistência ao desgaste e promover o endurecimento da liga conforme encontrado na literatura ${ }^{(3)}$. Os resultados obtidos com o tratamento a $650^{\circ} \mathrm{C}$ corroboram os trabalhos apresentados por outros autores ao verificarem que a resistência à corrosão do aço é fortemente afetada em tratamentos com temperaturas altas, devido à depleção de cromo e redução de passivação na liga, fenômeno discutido no início deste trabalho. Com a implantação de nitrogênio foram formados nitretos de cromo, implicando na redução de filme passivo de $\mathrm{Cr}_{2} \mathrm{O}_{3}$. Por outro lado, as melhorias em propriedades tribológicas e mecânicas como foi realizado neste trabalho, também são verificadas na literatura.

Em aplicações nas quais o material sofre algum tipo de solicitação mecânica sob cargas elevadas, torna-se viável aplicar o 3IP em alta temperatura principalmente quando a liga será empregada em ambientes pouco corrosivos.

\section{Referências}

1. G. da Silva, M. Ueda, J. O. Rossi, C. B. Mello. Influência da implantação iônica por imersão em plasma de nitrogênio nas propriedades superficiais do aço inoxidável 304. Revista Brasileira de Aplicações de Vácuo, v. 25, n. 4, 223-225, 2006.

2. M. Ueda, A. S. Geraldo, C. B. Mello e C. M. Lepienski. Plasma immersion ion implantation with auxiliary heating: application to SS304 stainless steel. Physica Status Solidi. C, Conferences and Critical Reviews, v. 5, p. 977-980, 2008.

3. M. Samandi, B. A. Shedden, D. I. Smith, G. A. Collins, R. Hutchings, J. Tendys. Microsctructure, corrosion and tribological behaviour of plasma immersion ion-implanted austenitic stainless steel. Surface and Coatings Technology 59 (1993) 261-266.

4. J. H. Liang, C. S. Wang, W. F. Tsai, C. F. Ai. Parametric study of nitrided AISI 304 austenite stainless steel prepared by plasma immersion ion implantation. Surface and Coatings Technology 201 (2007) 6638-6642.

5. C. E. Foerster, F. C. Serbena, S. L. R. da Silva, C. M. Lepienski, C. J. de M. Siqueira, M. Ueda. Mechanical and tribological properties of AISI 304 stainless steel nitrided by glow discharge compared to ion implantation and plasma immersion ion implantation. Nuclear Instruments and Methods in Physics Research B 257 (2007) 732-736.

6. L. Shen, L. Wang, Y. Wang, C. Wang. Plasma nitriding of AISI 304 austenitic stainless steel with pre-shot peening. Surface and Coatings Technology 204 (2010) 3222-3227.
Resultados do nosso grupo revelam a formação de camadas ricas em nitrogênio de até $20 \mu \mathrm{m}$ em ligas de Ti-4Al-6V devido à alta taxa de difusão favorecida com o processo 3IP em alta temperatura ${ }^{(13)}$. Com outro sistema 3IP similar ${ }^{(2)}$, o nitrogênio foi implantado no aço inoxidável 304 formando camadas de aproximadamente $5 \mu \mathrm{m}$.

É válido ressaltar que, embora a migração de cromo para os contornos de grão tenha prejudicado a resistência à corrosão da liga, o tratamento a $650^{\circ} \mathrm{C}$ utilizando $5 \mathrm{kV}$ é bastante interessante por ter realçado as propriedades tribológicas do aço inoxidável 304 produzindo um melhor desempenho que a liga modificada em temperatura mais baixa e empregando baixas energias.

\section{Agradecimentos}

Os autores agradecem à CAPES e FAPESP pelas bolsas de pós-graduação.

7. N. Mingolo, A. P. Tschiptschin, C. E. Pinedo. On the formation of expanded austenite during plasma nitriding of an AISI 316L austenitic stainless steel. Surface and Coatings Technology (2006) 4215-4218.

8. C. F. M. Borges, S. Hennecke, E. Pfender. Decreasing chromium precipitation in AISI 304 stainless steel during the plasma-nitriding process.Surface and Coatings Technology 123 (2000) 112-121.

9. H. Dong. S-phase surface engineering of $\mathrm{Fe}-\mathrm{Cr}, \mathrm{Co}-\mathrm{Cr}$ and Ni-Cr alloys. International Materials Reviews, v. 55, n. 2, p. 65-98, 2010.

10. Panossian, Z. Corrosão e protecão contra corrosão em equipamentos e estruturas metálicas - manual, v.1, São Paulo: Instituto de Pesquisas Tecnológicas, 1993.

11. R. M. Oliveira, J. A. N. Gonçalves, M. Ueda, J. O. Rossi, P. N. Rizzo. A new high-temperature plasma immersion ion implantation system with electron heating. Surface \& Coatings Technology, p. 3009-3012, 2010.

12. G99 - Standard Test Method for Wear Testing with a Pinon-Disk Apparatus in ASTM Standards, 2000.

13. R. M. Oliveira, C. B. Mello, G. Silva, J. A. N. Gonçalves, M. Ueda, L. Pichon. Improved properties of Ti6Al4V by means of nitrogen high temperature plasma based ion implantation. Surface and Coatings Technology 205 (2011) S111-S114. 